\title{
Crimmigratie en het uitzetten van strafrechtelijk veroordeelde vreemdelingen
}

\author{
Jelmer Brouwer ${ }^{*}$
}

In recente jaren zijn het strafrecht en het vreemdelingenrecht in toenemende mate met elkaar vervlochten geraakt, een proces dat door verschillende academici is aangeduid als crimmigratie (Brouwer e.a. 2017a; Stumpf 2006). Een van de consequenties hiervan is dat er steeds vaker vreemdelingenrechtelijke gevolgen worden verbonden aan het plegen van een strafbaar feit. Onlangs is er veel aandacht geweest voor het intrekken van het Nederlandse paspoort van veroordeelde Syriëgangers en andere jihadisten. Hoewel het voor veroordelingen voor reguliere strafbare feiten niet mogelijk is om iemand het Nederlanderschap af te nemen, is het in het afgelopen decennium wel steeds eenvoudiger geworden om de verblijfsvergunning van vreemdelingen $^{1}$ die niet genaturaliseerd zijn te beëindigen (Stronks 2013). Er bestaat inmiddels een breed pakket aan maatregelen om deze groep waar mogelijk Nederland uit te zetten, bij voorkeur in combinatie met een inreisverbod of ongewenstverklaring, zodat zij na hun uitzetting ${ }^{2}$ niet terugkeren naar Nederland (Laagland e.a. 2009). ${ }^{3}$

* J. Brouwer MSc E.MA is als promovendus verbonden aan het Instituut voor Strafrecht en Criminologie van de Universiteit Leiden. Delen van dit artikel zijn eerder verschenen in Brouwer 2017.

1 Met de term vreemdeling verwijs ik in dit artikel naar niet-Nederlanders die geen rechtmatig verblijf in Nederland (meer) hebben. Daarbij moet worden opgemerkt dat een overgroot deel van de 'vreemdelingen' wel rechtmatig in Nederland verblijft, maar deze bijdrage ziet niet op deze laatste groep.

2 In het Engels spreekt men gewoonlijk over deportation, maar in het Nederlands roept de term deportatie mijns inziens te veel associaties op met grootschalige verplaatsingen van groepen mensen op basis van politieke gronden. In dit artikel kies ik daarom voor uitzetting, een neutralere en in het Nederlands meer gebruikelijke term.

3 Zo is er sinds eind jaren negentig door middel van het zogeheten VRIS-protocol (VRIS staat voor Vreemdeling in de Strafrechtsketen) ingezet op verdere integratie van de strafrechtelijke en vreemdelingenrechtelijke processen en betere samenwerking tussen de betrokken instanties (Vreemdelingenpolitie, Koninklijke Marechaussee, IND, DJI en DT\&V). Het doel is om in een zo vroeg mogelijk stadium duidelijkheid te verkrijgen over de verblijfsrechtelijke status van een verdachte en na te gaan of er vreemdelingenrechtelijke gevolgen worden verbonden aan het strafbare feit. 
In deze bijdrage ga ik nader in op drie beleidswijzigingen die in recente jaren hebben plaatsgevonden ten aanzien van strafrechtelijk veroordeelde vreemdelingen: het herhaaldelijk aanscherpen van de glijdende schaal op basis waarvan wordt bepaald of een strafrechtelijk veroordeelde vreemdeling zijn verblijfsvergunning verliest, het samen in detentie plaatsen van strafrechtelijk veroordeelde vreemdelingen zonder verblijfsrecht en de regeling strafonderbreking, waarbij vreemdelingen zonder verblijfsrecht niet hun volledige straf hoeven uit te zitten indien zij terugkeren naar hun land van herkomst.

Hierna zal ik eerst nader ingaan op enkele theoretische aspecten omtrent vreemdelingen in de strafrechtsketen, waarbij ik in het bijzonder aandacht besteed aan de begrippen crimmigratie en bordered penality. Vervolgens zal ik de verschillende maatregelen bespreken in het licht van dit theoretische raamwerk. De centrale vraag bij het bespreken van deze drie maatregelen is in hoeverre strafrechtelijk veroordeelde vreemdelingen zichzelf in toenemende mate geconfronteerd zien met een moderne variant van de klassieke vorm van verbanning. Het artikel wordt afgesloten met een korte conclusie en discussie.

\section{Crimmigratie en bordered penality}

In zekere zin hebben het strafrecht en het vreemdelingenrecht altijd al bepaalde gelijkenissen gekend: beide systemen functioneren als poortwachter en richten zich op de vraag wie er volwaardig deel mag uitmaken van de samenleving (Aas 2013). Het strafrecht houdt zich echter bezig met de interne veiligheid en morele grenzen van de samenleving, terwijl het vreemdelingenrecht zich richt op de externe veiligheid en territoriale grenzen. Bovendien kennen beide rechtsgebieden fundamenteel andere uitkomsten. Strafrechtelijke handhaving resulteert in het uiterste geval in uitsluiting door middel van een gevangenisstraf, met meestal als uiteindelijk doel een terugkeer in diezelfde samenleving. Verwijdering uit de maatschappij door middel van het vreemdelingenrecht heeft daarentegen een meer permanent karakter, wat bereikt wordt door verwijdering van de betrokken persoon van het grondgebied (Stumpf 2013).

David Sklansky (2012) stelt dat crimmigratie niet los kan worden gezien van de bredere tendens van wat hij ad-hocinstrumentalisme 
noemt. Hiermee doelt hij op een manier van denken over het recht en juridische instanties waarin formeel onderscheid tussen rechtsgebieden van ondergeschikt belang is en overheidsfunctionarissen per individueel geval kunnen kiezen welk instrument het meest effectief is om een probleem op te lossen. Crimmigratie maakt het voor de autoriteiten mogelijk om een combinatie van beide instrumenten in te zetten om risicovolle individuen aan te pakken, of dat nu een crimineel, een vreemdeling of beiden is (Aas 2011; Fekete \& Webber 2010). Of die aanpak primair gebaseerd is op het vreemdelingenrecht of het strafrecht doet daarbij nauwelijks ter zake, zolang het beoogde doel maar wordt bereikt (Brouwer e.a. 2017b). Doordat handhaving via het strafrecht met aanzienlijk meer rechtswaarborgen is omkleed dan via het bestuursrecht, kan dit negatieve gevolgen hebben voor de rechtspositie van betrokken rechtssubjecten (Chacon 2012; Stumpf 2006; Van der Leun e.a. 2013). Verschillende auteurs hebben daarnaast gewezen op het risico dat crimmigratie leidt tot een groeiende groep 'buitenstaanders', doordat zowel het strafrecht als het vreemdelingenrecht in toenemende mate wordt ingezet om mensen buiten de samenleving te plaatsen (Sklansky 2012; Stumpf 2006; Van der Woude e.a. 2014). Crimmigratie heeft ook haar weerslag op de bestraffing van criminele vreemdelingen. Aas (2014) stelt dat op het moment dat strafrechtelijke interventies van toepassing zijn op vreemdelingen zonder verblijfsrecht, de nadruk aanzienlijk en meer openlijk op uitsluiting komt te liggen. Terwijl reguliere gevangenen resocialisatiemogelijkheden krijgen en een tweede kans verdienen, geldt dit niet voor vreemdelingen die geen onderdeel (meer) zijn van de gemeenschap (Fekete \& Webber 2010; Griffiths 2015). Dit onderscheid resulteert uiteindelijk in een parallel strafrechtssysteem voor vreemdelingen - Aas noemt dit bordered penality-, waarin het uitzetten van gedetineerden de belangrijkste doelstelling wordt (Aas 2014). Dit lijkt in veel gevallen dan ook gelijkenissen te vertonen met de klassieke verbanning.

Verschillende auteurs hebben in de afgelopen jaren een vergelijkbare trend in Nederland vastgesteld. In navolging van Cavadino en Dignan (2006) stelt Boone (2012) dat er in Nederland sprake is van 'bifurcatie': een systeem waarbij er sprake is van een tweedeling tussen 'insluitende' en 'uitsluitende' straffen. Kenmerkend voor de uitsluitende straffen is dat zij 'delictplegers afhouden van deelname aan de samenleving en (...) ook niet gericht zijn op een voorbereiding van de terugkeer naar die samenleving' (Boone 2012, p. 7). Van Swaaningen (2005, 
p. 296) spreekt in dit verband van maatregelen die omschreven kunnen worden als 'banishment modern style'. Boone (2012) toont aan dat de scheidslijn tussen insluitende en uitsluitende straffen vaak wordt bepaald door de afwezigheid van een verblijfsvergunning. Daarmee vertoont deze vorm van bifurcatie dan ook veel gelijkenissen met Aas' (2014) bordered penality.

In de volgende paragrafen ga ik na in hoeverre het beleid ten aanzien van strafrechtelijk veroordeelde vreemdelingen past binnen deze bredere ontwikkelingen. Daartoe richt ik me op drie recente maatregelen die bijdragen aan een steeds strenger beleid ten aanzien van criminele vreemdelingen: de aanscherpingen van de glijdende schaal, het samenplaatsen in detentie van strafrechtelijk veroordeelde vreemdelingen en de regeling strafonderbreking.

\section{Aanscherpingen glijdende schaal}

Vreemdelingen moeten in Nederland voorzichtiger zijn dan Nederlanders. Als ze een strafbaar feit plegen, wacht niet alleen een mogelijke strafrechtelijke veroordeling, maar kan ook hun verblijfsvergunning worden ingetrokken door de Immigratie- en Naturalisatie Dienst (IND). Dat kan echter niet altijd, het hangt af van de ernst van het strafbare feit en de duur van het rechtmatige verblijf van de vreemdeling. Sinds 1990 is deze afweging geobjectiveerd in de zogenoemde glijdende schaal. Daarin zijn de ernst van het strafbare feit en de duur van het verblijf tegen elkaar afgezet en staat precies bepaald wanneer de verblijfsvergunning kan worden ingetrokken (Stronks 2013). De gedachte hierachter is dat er een afweging wordt gemaakt tussen de mate van integratie enerzijds en de ernst van de inbreuk voor de samenleving anderzijds. Hoe langer iemand reeds in Nederland verblijft, hoe zwaarder het delict dient te zijn om te resulteren in intrekking van de verblijfsvergunning.

Aanvankelijk werd de glijdende schaal geïntroduceerd om de rechtszekerheid voor vreemdelingen te vergroten. De afgelopen jaren is deze regeling echter ontdekt als geschikt beleidsinstrument om een zichtbaar streng migratiebeleid te voeren. Dit heeft ertoe geleid dat de glijdende schaal herhaaldelijk is aangescherpt (Stronks 2013). Dit betekent niet alleen dat recente immigranten sneller hun verblijfsvergunning verliezen als gevolg van een strafrechtelijke veroordeling, maar 
ook dat het eenvoudiger is geworden om de verblijfsvergunning in te trekken van niet-Nederlanders die al geruime tijd in Nederland verblijven.

Bij de meest recente aanscherping in 2012 is voor bepaalde delicten zelfs de einddatum opgeheven: waar een niet-genaturaliseerde rechtmatig verblijvende vreemdeling voorheen na twintig jaar niet meer uitgezet kon worden, is dat nu niet langer het geval. In het geval van drugs-, gewelds- en zedenmisdrijven waar een gevangenisstraf van twee jaar of meer voor staat, kan iedere vreemdeling - ongeacht de duur van het legale verblijf - zijn of haar verblijfsstatus verliezen. ${ }^{4}$ Dit betekent dat zelfs als iemand in Nederland is geboren of zich hier op zeer jonge leeftijd heeft gevestigd, en om wat voor reden dan ook nooit het Nederlanderschap heeft verkregen, nog kan worden uitgezet.

Vreemdelingen verworden hierdoor 'eternal guests', die te maken krijgen met 'eindeloze voorwaardelijkheid' (Kanstroom 2000; Stronks 2013).

Als gevolg van deze aanpassingen is het aantal ingetrokken reguliere verblijfsvergunningen - dus exclusief ingetrokken asielvergunningen toegenomen van 20 in 2013 naar 80 in 2016 (zie ook Boone \& Kurtovic 2016). ${ }^{5}$ Deze stijging is nog relatief beperkt, omdat in de praktijk de gevolgen van de aanpassingen van de glijdende schaal regelmatig worden ingeperkt in de rechtbank. Zo moet worden aangetoond dat de maatregel proportioneel is en opweegt tegen de persoonlijke gevolgen voor de vreemdeling. Daarnaast moet ingevolge een uitspraak van het Hof van Justitie van de Europese Unie per individueel geval worden aangetoond dat de vreemdeling een daadwerkelijk en actueel gevaar voor de openbare orde vormt. ${ }^{6}$ Zo is het beleid in de praktijk dus niet zo repressief als aanvankelijk door de politiek was beoogd. ${ }^{7}$

4 Kamerstukken // 2011/12, 19673, 1494.

5 Overzicht van het aantal intrekkingen van verblijfsvergunningen en het aantal uitzettingen van vreemdelingen en criminele vreemdelingen. Te raadplegen via: www.rijksoverheid.nl/ binaries/rijksoverheid/documenten/publicaties/2017/07/13/overzicht-van-het-aantalintrekkingen-van-verblijfsvergunningen-en-het-aantal-uitzettingen-van-vreemdelingen-encriminele-vreemdelingen/Cijfers+intrekkingen+en+uitzettingen.pdf.

6 HvJ EU 11 juni 2015, C-554/13, ECLI:EU:C:2015:377 (Z.Zh. en I.O./Staatssecretaris van Veiligheid en Justitie).

7 Zie ook 'Criminele vreemdeling wordt maar zelden uitgezet, rechters bemoeilijken intrekken verblijfsstatus', de Volkskrant 13 juli 2017. Te raadplegen via: www.volkskrant.nl/ binnenland/criminele-vreemdeling-wordt-maar-zelden-uitgezet-rechters-bemoeilijkenintrekken-verblijfsstatus a4506018/. 


\section{Het samenplaatsen van strafrechtelijk veroordeelde vreemdelingen}

In navolging van onder andere het Verenigd Koninkrijk en Noorwegen beschikt ook Nederland sinds enkele jaren over een gevangenis uitsluitend bestemd voor strafrechtelijk veroordeelde vreemdelingen. De Penitentiaire Inrichting (PI) Ter Apel is sinds 2012 een specifieke inrichting voor vreemdelingen in de strafrechtsketen (VRIS). Dit houdt in dat hier enkel mannen gedetineerd zitten die een misdrijf hebben begaan en geen rechtmatig verblijf in Nederland (meer) hebben. Voor al deze gedetineerden geldt dan ook dat zij in principe niet meer dienen terug te keren in de Nederlandse samenleving.

Het regime in Ter Apel is aanmerkelijk soberder dan in reguliere PI's doordat activiteiten gericht op resocialisatie grotendeels ontbreken. De belangrijkste reden hiervoor is dat terugkeer in de samenleving voor deze groep gedetineerden niet aan de orde is; zij dienen immers na het uitzitten van hun straf teruggestuurd te worden naar het land van herkomst of een ander land waar zij legaal kunnen verblijven. De toenmalige staatssecretaris van Justitie beargumenteerde in het voorstel voor een specifieke VRIS-locatie dat 'deze groep (...) zich in die mate van andere (groepen) gedetineerden [onderscheidt] dat resocialisatie gericht op terugkeer in de Nederlandse samenleving niet aan de orde is en beginselen als verlof, regionalisering en detentiefasering niet aan de orde zijn' (RSJ 2008, p. 6). Zoals Boone en Kox (2012) al eerder opmerkten, is dit uitgangspunt wel enigszins opmerkelijk: de Hoge Raad besliste reeds in 1987 dat resocialisatie niet enkel is voorbehouden aan gedetineerden die na hun gevangenisstraf terugkeren in de Nederlandse samenleving.

Het afzonderlijk bij elkaar plaatsen van strafrechtelijk veroordeelde vreemdelingen past in veel opzichten binnen Aas' (2014) notie van bordered penality. Ten eerste is het regime aanmerkelijk soberder dan voor reguliere gedetineerden, hoewel er in de praktijk door sommige penitentiair inrichtingswerkers toch gepoogd wordt om op kleine schaal activiteiten voor de gedetineerde vreemdelingen te organiseren (Brouwer 2017). Daarnaast is verwijdering van het Nederlandse grondgebied een uitdrukkelijke doelstelling van de gevangenisstraf (Schoep 2013). Medewerkers van de Dienst Terugkeer en Vertrek (DT\&V) - zogeheten regievoerders - zijn werkzaam in de PI om het daadwerkelijke vertrek van een vreemdeling te organiseren. $\mathrm{Zij}$ hebben vrij toegang tot de PI en voeren op regelmatige basis gesprekken met vreem- 
delingen. Deze gesprekken kunnen bedoeld zijn om praktische zaken te regelen, maar ook om vreemdelingen te motiveren om mee te werken aan hun eigen terugkeer.

Van veel vreemdelingen in de PI Ter Apel zijn documenten voorhanden, wat het organiseren van terugkeer doorgaans niet al te ingewikkeld maakt. Indien de regievoerder echter niet over de documenten van een vreemdeling beschikt, is deze in veel gevallen afhankelijk van de medewerking van de vreemdeling om zijn identiteit en land van herkomst vast te stellen. Vreemdelingen die in Nederland willen verblijven, kunnen zodoende door het verschaffen van een valse naam of nationaliteit, of het simpelweg verzwijgen van de eigen identiteit, terugkeer naar hun land van herkomst onmogelijk maken. Om deze problematiek te ondervangen en criminele vreemdelingen aan te sporen mee te werken aan hun eigen uitzetting, is enkele jaren geleden de regeling Strafonderbreking geïntroduceerd.

\section{Regeling Strafonderbreking}

Sinds 2012 komen strafrechtelijk veroordeelde vreemdelingen zonder rechtmatig verblijf in Nederland niet meer in aanmerking voor voorwaardelijke invrijheidstelling. De minister was van mening dat de voorwaardelijke invrijheidstelling een instrument is om gedetineerden op een gecontroleerde manier te laten terugkeren in de samenleving. Hierdoor is dit in principe niet van toepassing op onrechtmatig verblijvende vreemdelingen, daar zij niet terugkeren in de Nederlandse maatschappij (Schoep 2012). Het gevolg is dat met ingang van 1 april 2012 artikel 15 lid 3 onder c van het Wetboek van Strafrecht (Sr) voorwaardelijke invrijheidstelling niet van toepassing verklaart als 'de veroordeelde een vreemdeling is die geen rechtmatig verblijf heeft in Nederland in de zin van artikel 8 van de Vreemdelingenwet'. In plaats van de voorwaardelijke invrijheidstelling is voor deze groep gedetineerden de regeling Strafonderbreking (SOB) in het leven geroepen, die in afwachting van een definitieve wet is vastgelegd in artikel 40a van de Regeling tijdelijk verlaten van de inrichting (Rtvi). Dit artikel biedt de minister van Justitie en Veiligheid de mogelijkheid om de tenuitvoerlegging van een gevangenisstraf van een vreemdeling voor onbepaalde tijd te onderbreken op grond van artikel 570b van het Wetboek van Strafvordering (Sv). Hierin is vastgelegd dat de minister 
de tenuitvoerlegging van een vrijheidsstraf kan onderbreken. Strafonderbreking is dan ook uitdrukkelijk geen recht, maar een gunst verleend door de minister van Justitie en Veiligheid. Doorgaans geeft een regievoerder aan dat een vreemdeling kan worden uitgezet, waarna medewerkers van de Dienst Justitiële Inrichtingen (DJI) de beslissing van de minister voorbereiden. SOB kan worden aangevraagd door de vreemdeling, maar in de praktijk begint de regievoerder de procedure ook als de gedetineerde geen aanvraag heeft ingediend.

Om voor SOB in aanmerking te komen dient een vreemdeling aan een aantal voorwaarden te voldoen, die zijn vastgelegd in artikel 40a lid 4 Rtvi. Ten eerste moet er sprake zijn van een onherroepelijke veroordeling; er mag dus geen hoger beroep of cassatie meer lopen. Daarnaast wordt strafonderbreking enkel verleend indien de vreemdeling Nederland daadwerkelijk verlaat. In de praktijk betekent dit dat de DT\&V signaleert dat vertrek direct vanuit de PI daadwerkelijk mogelijk is. Tot slot mag een vreemdeling die via de SOB-maatregel uit Nederland vertrekt niet meer terugkeren; indien hij toch weer wordt aangetroffen in Nederland, zal hij zijn strafrestant alsnog moeten uitzitten (Schoep 2012). Deze 'verbanning' is in principe voor onbepaalde tijd. SOB wordt normaal gesproken ook maar één keer verleend: indien een uitgezette vreemdeling terugkeert naar Nederland en opgepakt wordt, komt hij niet meer in aanmerking voor SOB.

Artikel 40a lid 2 Rtvi bepaalt dat vreemdelingen die een gevangenisstraf van meer dan drie jaar uitzitten, in aanmerking komen voor strafonderbreking na het uitzitten van ten minste twee derde van hun straf. Aan vreemdelingen die veroordeeld zijn tot een gevangenisstraf van maximaal drie jaar kan strafonderbreking worden verleend nadat minstens de helft van de straf is ondergaan. In dat geval komen zij eerder vrij dan reguliere gedetineerden, ${ }^{8}$ hetgeen suggereert dat een zo snel mogelijke uitzetting een primaire doelstelling is van de strafrechtelijke

8 Art. $15 \mathrm{Sr}$ stelt dat gedetineerden met een gevangenisstraf tot een jaar niet in aanmerking komen voor vervroegde invrijheidstelling. Veroordeelden met een gevangenisstraf van minimaal één en maximaal twee jaar worden in vrijheid gesteld als zij het eerste jaar volledig hebben uitgezeten en van het overige deel een derde. Betreft het een gevangenisstraf van meer dan twee jaar, dan dient twee derde van de straf te worden uitgezeten (Schuyt 2010). Gedetineerden die niet aan de algemene en bijzondere voorwaarden voldoen die aan de vervroegde invrijheidstelling worden verbonden, worden echter eveneens langduriger uitgesloten van de samenleving. In die zin worden ook sommige reguliere gedetineerden geconfronteerd met de uitsluitende kant van bifurcatie. 
detentie voor vreemdelingen. ${ }^{9}$ Tegelijkertijd draagt dit ook weer bij aan een vorm van rechtsgelijkheid met gedetineerden met de Nederlandse nationaliteit, nu vreemdelingen die Nederland verlaten geen langere straf uitzitten dan reguliere gedetineerden. Zoals elders geïllustreerd hangt het sterk af van de wens van vreemdelingen om in Nederland te blijven of zij dit als oneerlijk ervaren (Brouwer 2017).

Doordat de voorwaardelijke invrijheidstelling wordt gezien als een belangrijke stap in het resocialisatieproces, wekt het geen verbazing dat strafrechtelijk veroordeelde vreemdelingen hiervan worden uitgesloten. Wat de SOB-maatregel echter tot een noviteit maakt, is dat het strafrecht expliciet wordt ingezet om vreemdelingen te motiveren uit Nederland te vertrekken. In de nota van wijziging van artikel $15 \mathrm{Sr}$ beargumenteerde de minister dat de maatregel 'een bijdrage kan leveren aan de bereidheid van illegale vreemdelingen om Nederland te verlaten'.${ }^{10}$ De maatregel is bedoeld om vreemdelingen die hun eigen uitzetting frustreren, door bijvoorbeeld geen identificatiedocumenten te overleggen, te motiveren om toch mee te werken aan vertrek uit Nederland. De SOB-maatregel past op deze wijze duidelijk binnen de bredere trend van crimmigratie, doordat wordt getracht om bepaalde vreemdelingenrechtelijke doelen, namelijk het verwijderen van ongewenste vreemdelingen van het Nederlandse grondgebied, te bereiken door middel van de inzet van een gebifurceerde strafrechtelijke modaliteit. De SOB-maatregel lijkt dan ook bij uitstek binnen de logica van crimmigratie, ad-hocinstrumentalisme en bordered penality te passen.

\section{Conclusie en discussie}

In recente jaren is het beleid ten aanzien van strafrechtelijk veroordeelde vreemdelingen op verschillende manieren flink aangescherpt. Ten eerste is het eenvoudiger geworden om de verblijfsvergunning van een vreemdeling in te trekken naar aanleiding van een strafbaar feit. Meer vreemdelingen zullen hierdoor hun verblijfsrecht verliezen

9 Een goed voorbeeld hiervan is de ophef die verleden jaar ontstond toen een Poolse gedetineerde die was veroordeeld voor het doodrijden van drie mensen vrijkwam met strafonderbreking, nadat hij iets meer dan de helft van zijn straf had uitgezeten. Zie “'Zwangerschapsverlof" zet streep door celstraf Poolse doodrijder peuter', NOS 13 mei 2017. Te raadplegen via: https://nos.nl/artikel/2172910-zwangerschapsverlof-zet-streep-doorcelstraf-poolse-doodrijder-peuter.html.

10 Kamerstukken // 2010/11, 32319, 8, p. 9. 
en Nederland dienen te verlaten na het uitzitten van hun straf. Daarnaast is er voor strafrechtelijk veroordeelde vreemdelingen een specifieke PI, waar weinig mogelijkheden zijn voor resocialisatieactiviteiten en de nadruk ligt op uitzetting uit Nederland. Tot slot zet de SOBmaatregel een strafrechtelijke modaliteit in om een vreemdelingenrechtelijke doelstelling - verwijdering van het Nederlandse grondgebied - te bereiken.

De verschillende maatregelen dragen bij aan de bifurcatie van het Nederlandse strafrechtssysteem, waarbij er onderscheid gemaakt wordt tussen insluitende en uitsluitende straffen. Doordat strafrechtelijk veroordeelde vreemdelingen niet terug dienen te keren in de Nederlandse samenleving komen zij ook niet in aanmerking voor resocialisatiemogelijkheden. In plaats daarvan wordt verwijdering uit Nederland een belangrijk doel van het strafrecht. Ik heb in dit artikel dan ook betoogd dat al deze maatregelen goed passen binnen de theoretische noties van crimmigratie en bordered penality. Tegelijkertijd zijn er ook belangrijke nuances te plaatsen bij de notie dat gedetineerde vreemdelingen in alle opzichten slechter af zijn dan gedetineerden met de Nederlandse nationaliteit. Zo kan de SOB-maatregel juist gunstig uitpakken voor strafrechtelijk gedetineerde vreemdelingen en trachten penitentiair inrichtingswerkers in Ter Apel binnen de beperkte mogelijkheden die zij hebben vaak toch iets aan activiteiten voor de gedetineerden te organiseren (Brouwer 2017).

Niettemin is duidelijk dat ten aanzien van strafrechtelijk veroordeelde vreemdelingen in veel gevallen het ultieme doel van straf permanente verwijdering uit de Nederlandse samenleving is. Betoogd kan dan ook worden dat deze gedetineerden zichzelf geconfronteerd zien met een moderne variant van de klassieke verbanning. Gezien het huidige klimaat ten aanzien van zowel criminaliteit als migratie wekt dit wellicht geen verbazing; zoals elders aangetoond is het aanpakken van criminele vreemdelingen iets waar alle politieke partijen het over eens kunnen zijn (Brouwer e.a. 2017a). Tegelijkertijd roept dit wel de vraag op hoe het gesteld is met de fundamentele rechten van vreemdelingen in Nederland. In hoeverre is een afwijkend beleid ten aanzien van deze groep gerechtvaardigd op basis van het feit dat zij geen volwaardig lid zijn van de samenleving en na hoeveel jaar hebben zij dan wel recht op een behandeling die gelijkwaardig is aan die van 'onze' criminelen (cf. Boone 2012; Stronks 2013)? 


\section{Literatuur}

\section{Aas 2011}

K.F. Aas, “"Crimmigrant” bodies and bona fide travelers: Surveillance, citizenship and global governance', Theoretical Criminology (15) 2011, afl. 3, p. 331-346.

\section{Aas 2013}

K.F. Aas, 'The ordered and the bordered society: Migration control, citizenship, and the northern penal state', in: K.F. Aas \& M. Bosworth (red.), The borders of punishment: Migration, citizenship, and social exclusion, Oxford: Oxford University Press 2013, p. 21-39.

\section{Aas 2014}

K.F. Aas, 'Bordered penality: Precarious membership and abnormal justice', Punishment \& Society (16) 2014, afl. 5, p. 520-541.

\section{Boone 2012}

M. Boone, Our own rascals first: Inclusion and exclusion in the use of sanctions, Den Haag: Eleven International Publishing 2012.

\section{Boone \& Kox 2012}

M. Boone \& M. Kox, 'What works for irregular migrants in the Netherlands?', European Journal of Probation (4) 2012, afl. 3, p. 54-68.

\section{Boone \& Kurtovic 2016}

M. Boone \& E. Kurtovic, 'Bijkomende gevolgen van straf en het principe van proportionele strafoplegging', Nederlands Juristenblad 2016, afl. 23, p. 1623-1629.

\section{Brouwer 2017}

J. Brouwer, 'Uitzetten of uitzitten? Crimmigratie en strafonderbreking voor vreemdelingen zonder rechtmatig verblijf', in: P. van Berlo, J.P. Cnossen, T.J.M. Dekkers, J.V.O.R. Doekhie, L. Noyon \& M. Samadi (red.), Over de grenzen van de discipline. Interaction between and within criminal law and criminology, Den Haag: Boom juridisch 2017, p. 31-48.

\section{Brouwer e.a. 2017a}

J. Brouwer, M.A.H. van der Woude \& P. van der Leun, 'Framing migration and the process of crimmigration: A systematic analysis of the media representation of unauthorised immigrants in the Netherlands', European Journal of Criminology (14) 2017, afl. 1, p. 100-119.

\section{Brouwer e.a. 2017b}

J. Brouwer, M. van der Woude \& J. van der Leun, 'Op de grens van het vreemdelingentoezicht: discretionaire beslissingen binnen het Mobiel Toezicht Veiligheid', Tijdschrift voor Veiligheid (16) 2017, afl. 2, p. 73-89. 


\section{Cavadino \& Dignan 2006}

M. Cavadino \& J. Dignan, Penal systems. A comparative approach, Londen: Sage 2006.

\section{Chacon 2012}

J.M. Chacon, 'Overcriminalizing immigration', The Journal of Criminal Law \& Criminology (102) 2012, afl. 3, p. 613-653.

\section{Fekete \& Webber 2010}

L. Fekete \& F. Webber, 'Foreign nationals, enemy penology and the criminal justice system', Race \& Class (51) 2010, afl. 4, p. 1-25.

\section{Griffiths 2015}

M. Griffiths, 'The convergence of the criminal and the foreigner in the production of citizenship', in: B. Anderson \& V. Hughes (red.), Citizenship and its others, Londen: Palgrave Macmillan 2015, p. 72-88.

\section{Kanstroom 2000}

D. Kanstroom, 'Deportation, social control, and punishment: Some thoughts about why hard laws make bad cases', Harvard Law Review 2000, afl. 11, p. 1889-1935.

\section{Laagland e.a. 2009}

D.C. Laagland, J.P. van der Leun, P.P. van der Meij \& A. Leerkes, 'Het strafrecht als vicieus sluitstuk van het beleid ten aanzien van criminele vreemdelingen. Het sluimerende probleem van de niet-uitzetbare ongewenst verklaarde', Delikt en Delinkwent (52) 2009, p. 697-724.

\section{Van der Leun e.a. 2013}

J.P. van der Leun, M.A.H. van der Woude \& S. de Ridder, 'Crimmigratie in de lage landen: smeltende grenzen?', Strafblad (11) 2013, afl. 3, p. 221-228.

\section{RSJ 2008}

Raad voor Strafrechtstoepassing en Jeugdbescherming (RSJ), Het samen plaatsen van strafrechtelijk gedetineerde vreemdelingen die geen rechtmatig verblijf in Nederland hebben, 2008, www.rsj.nl/binaries/adviesstrafrechtelijk-gedetineerdevreemdelingen_tcm26-26489.pdf.

\section{Schoep 2012}

G.K. Schoep, 'Strafonderbreking bij illegale vreemdelingen', Delikt en Delinkwent (42) 2012, p. 1-16.

\section{Schoep 2013}

G.K. Schoep, 'Strafrechtelijk gedetineerde vreemdelingen', Strafblad 2013, afl. 11, p. 239-247.

\section{Schuyt 2010}

P. Schuyt, 'De voorwaardelijke invrijheidstelling en de calculerende rechter', PROCES (89) 2010, afl. 2, p. 105-111.

\section{Sklansky 2012}

D.A. Sklansky, 'Crime, immigration, and ad hoc instrumentalism', New Criminal Law Review (15) 2012, afl. 2, p. 157-223. 


\section{Stronks 2013}

M. Stronks, 'Een bijna ongebreidelde beteugeling van de tijd.

Een analyse van aanscherpingen van de glijdende schaal', Nederlands Juristenblad 2013, afl. 34, p. 2306-2314.

\section{Stumpf 2006}

J.P. Stumpf, 'The crimmigration crisis: Immigrants, crime, and sovereign power', American University Law Review (56) 2006, afl. 2, p. 367-420.

\section{Stumpf 2013}

J.P. Stumpf, 'Two profiles of crimmigration law: Criminal deportation and illegal migration', in: F. Pakes (red.), Globalisation and the challenge to criminology, New York: Routledge 2013, p. 91-109.

\section{Van Swaaningen 2005}

R. van Swaaningen, 'Public safety and the management of fear', Theoretical Criminology (9) 2005, afl. 3, p. 289-305.

\section{Van der Woude e.a. 2014}

M.A.H. van der Woude, J.P. van der Leun \& J.A. Nijland, 'Crimmigration in the Netherlands', Law \& Social Inquiry (39) 2014, afl. 3, p. 560-579. 